\title{
Cohort Effect and the Impact of Environmental Characteristics on Obesity
}

\author{
Yuval Arbel (Corresponding author) \\ Sir Harry Solomon School of Economics and Management \\ Western Galilee College, Acre 2412101, Israel \\ E-mail:YuvalAr@wgalil.ac.il
}

\begin{abstract}
Chaim Fialkoff
Institute of Urban and Regional Studies, Hebrew University of Jerusalem

Mt. Scopus, Jerusalem, 9190501, Israel

E-mail: cfialk@gmail.com
\end{abstract}

\author{
Amichai Kerner \\ Netanya Academic College, Netanya 4223587, Israel \\ E-mail: kerneram@netvision.net.il
}

Received: December 10, 2018 Accepted: December 27, 2018 Published: January 28, 2019

doi:10.5296/ber.v9i1.14289 URL: https://doi.org/10.5296/ber.v9i1.14289

\begin{abstract}
Obesity and overweight have become the fourth leading risk factor for global mortality. They might be affected by a variety of different externalities, such as processed food, traffic noise, and other environmental factors. The objective of the current study is to examine the impact of cohort, gender and environmental characteristics of the residential unit on overweight and obesity. We make use of an extensive and unique set of questions concerning the environmental characteristics of the housing unit asked within the framework of the 2015-2016 longitudinal survey conducted by the Israeli Central Bureau of Statistics (CBS) via face-to-face interviews. The survey also includes information regarding the weight, height, gender and age of each household member. The opportunity to use the BMI measure, namely, $W E I G H T \div\left(H E I G H T^{2}\right)$, and estimate the probability to become overweight $(B M I \geq 25)$
\end{abstract}


provides unique measures of the impacts of environmental externalities. The prominent public policy reprecussion from our study is that a reduction in traffic noise, may improve residents health, as they lead to a decrease in the prbability of overweight for both genders. Further implication is that positive environmental characteristics, particularly, number of exposures in the residential unit, tends to improve significantly the probabity of overweight among women.

Keywords: Body mass index, Obesity, Cohort effect, Environmental characteristics

\section{Introduction}

Obesity and overweight have become the fourth leading risk factor for global mortality, responsible for an estimated 3.2-5.0 million deaths annually (Sallis et al., 2016; World Health Organization Report, 2018). A known measure of obesity is called "Body Mass Index" (BMI), which is calculated as WEIGHT $\div\left(H E I G H T^{2}\right)$ where WEIGHT is measured in kilograms and HEIGHT is measured in meters. A widely adopted definition of overweight is a body mass index (BMI) greater than or equal to 25, with obesity defined as BMI $\geq 30$ (OECD, 2016; Qin and Pan, 2016). Obesity is also related to housing choice opportunities as they affect the level of physical activities (Creatore et al., 2016; Salis et al., 2016).

Following Arbel et al. (2018), the objective of the current study is to examine the impact of cohort, gender and environmental characteristics of the residential unit on overweight and obesity. Measuring the cost and benefit associated with externalities in general, and environmental externalities in particular, might prove to be a difficult task (e.g., Acemouglo and Angrist, 1999). Yet, given that "[e]xternalities cause inefficiencies" (O'Sullivan, 2012: 9-10) this task might prove to be important. In the case of negative (positive) externality, people pay (get) less than the social cost (benefit) of driving (education), respectively, so they drive too much (stop short of the socially efficient level of education). The possibilities of using the BMI measure, and estimate the probability to become overweight $(B M I \geq 25)$ provide unique ways to quantify the impacts of these environmental externalities.

We make use of an extensive set of questions concerning the environmental characteristics of the housing unit asked within the framework of the 2015-2016 longitudinal survey conducted by the Israeli Central Bureau of Statistics (CBS). The survey also includes information regarding the weight, height, gender and age of each household member. The sample of this survey is representative of the Israeli population, and the common method used to collect the data from the sampled households is face-to-face interviews at the respondents' homes via computerized questionnaires.

The outcomes of our study show a condition of overweight among 48.17\% (55.59\%) of the Israeli female (male) respondents for all adult cohorts above 20 years. Moreover, the projected probability of overweight becomes $70 \%-75 \%$ for $60-80$ years cohorts.

Referring to the environmental features, while projected BMI and probability of overweight drop significantly with positive environmental characteristics, such as the number of exposures (by $3.32 \%$ for women for each additional exposure), and a view of a green space from the largest window in an urban area (by $2.58 \%-4.77 \%$ for women), both dependent 
variables rise significantly with negative environmental characteristics, such as traffic noise (by $2.30 \%-7.28 \%$ for women and 2.29\%-6.08\% for men), a view of a highway $(1.34 \%-6.18 \%$ for men), and a view of an internal road from the largest window (1.66\%-4.92\% for men).

In line with related medical studies, the findings emphasize the impact of cohort and environmental characteristics on obesity, particularly those associated with exposures, a view of green space in an urban area on the one hand, and traffic noise and a view of a highway and an internal road on the other. Referring to traffic noise, for example, by exposing 18 respondents to traffic noise in the laboratory, Hemmingsen et al., (2015) found oxidative stress and damage to the DNA. Referring to sleeping disorders, Bodin et al., (2015) found a reduction in the level of reported sleeping annoyance in housing units with a quiet side than those having at least one window facing a yard, garden or green space

With the exception of traffic noise, the findings further indicate gender differences with respect to the former variables, namely, building exposures and green space, and the latter variables, namely, a view of a highway and an internal road. Moreover, and unlike their male counterparts, projected BMI of females rises significantly (at the $1 \%$ significance level) by $0.92 \%-0.97 \%$ for each additional child.

The rest of this paper is organized as follows. Section 2 provides descriptive statistics. Section 3 presents the empirical model and reports the results. Finally, Section 4 concludes and summarizes.

\section{Sample and Controls}

The data for this study are based on the longitudinal survey carried out by the Israeli Central Bureau of Statistics in 2014-2015 and 2016. As an OECD member from 2010, Israel is required to conduct such a survey. A detailed description of outcome reproduction from the raw data files in Stata software package is given at Appendix S1.

The sample of this survey is representative of the Israeli population, which includes all the Israeli households, and persons living in non-therapeutic institutions, namely, students in dormitories, assisted living for the elderly and absorption centers for new immigrants. The definition of the Israeli population excludes prisoners, inhabitants in therapeutic institutions, such as chronic care housing for the elderly, Israeli inhabitants who remained outside the country for at least one year, foreign workers, diplomats, and Bedouins living in scattered settlements in the southern part of Israel.

The common method used to collect the data from the sampled households is face-to-face interviews at the respondents' homes via computerized questionnaires. Interviews were held with each adult household member above 17 years old, in one of three languages (Hebrew, Arabic and Russian).

Given that several studies in the field use telephone interviews (e.g., Stark et al., 2014; Adachi-Mejia et al., 2017), the face-to-face interview technique provides two main advantages: 1) unlike phone interviews, the respondent answers the questionnaire in a non-threatening environment with reduced tendency to avoid answers; 2) the interviewer can 
test immediately the reliability of answers, particularly regarding environmental housing conditions, height and weight of each household member, and add personal impressions.

Table 1 presents the descriptive statistics of the variables used in the subsequent regression analysis. The table refers to 2,904 observations $\times$ years for cohorts of adults above 20 years old, participating in the 2015-2016 longitudinal survey carried out by the Israeli Central Bureau of Statistics. The group of female (male) respondents are members of 962 (956) households.

Table 1. Descriptive Statistics Panel 2015-2016

\begin{tabular}{|c|c|c|c|c|c|c|}
\hline VARIABLES & Description of the Variables & Obs. & Mean & STD & Min & Max \\
\hline BMI & $\begin{array}{l}\frac{W E I G H T}{H E I G H T^{2}} \text { where WEIGHT is measured in } \\
\text { kilograms and HEIGHT is measured in meters }\end{array}$ & 2,904 & 25.87 & 4.55 & 14.87 & 43.02 \\
\hline BMI25 & $1=B M I \geq 25 ; 0=$ otherwise & 2,904 & $51.89 \%$ & $49.97 \%$ & 0 & 1 \\
\hline AGE & Age in years $(21-80)$ & 2,904 & 43.58 & 16.46 & 21 & 80 \\
\hline HHSIZE & Number of persons in the household & 2,904 & 3.60 & 1.90 & 1 & 11 \\
\hline EXPOSURES & Number of exposures in the apartment & 2,776 & 2.73 & 0.97 & 1 & 4 \\
\hline GREEN_SPACE & $\begin{array}{l}1=\text { View of a green space from the largest } \\
\text { window of the apartment; } 0=\text { othewise }\end{array}$ & 2,903 & $18.43 \%$ & $38.78 \%$ & 0 & 1 \\
\hline TRAFFIC_NOISE & $1=$ Traffic noise from the road; $0=$ otherwise & 2,904 & $41.73 \%$ & $49.32 \%$ & 0 & 1 \\
\hline VIEW_HIGHWAY & $\begin{array}{l}1=\text { View of a highway from the largest } \\
\text { window of the apartment; } 0=\text { otherwise }\end{array}$ & 2,903 & $23.01 \%$ & $42.10 \%$ & 0 & 1 \\
\hline VIEW_INTERNAL & $\begin{array}{l}1=\text { View of an internal road from the largest } \\
\text { window of the apartment; } 0=\text { otherwise }\end{array}$ & 2,903 & $63.66 \%$ & $48.11 \%$ & 0 & 1 \\
\hline
\end{tabular}

Notes: The sample includes 2,904 observations xyears of persons who reported on environmental characteristics and number of exposures, covering up to two years (2015-2016), where the age of female (male) members were restricted to 21 years or older.

As can be seen from the table, the BMI at the sample mean is 25.87 and the standard deviation is 4.55 (BMI). The $99 \%$ confidence interval for the pooled sample is $25.65 \leq$ average $(B M I) \leq 26.08$. Based on the standard criterion of overweight, namely, average $(B M I)$ $\geq 25$, the implication obtained from these statistical test outcomes is that respondents included in the survey suffer from overweight. Indeed, $51.89 \%$ of the repondents $\times y e a r s$ are overweight (BMI25).

Figure 1 demonstrates the distribution of overweight across gender. While $55.59 \%$ of the male respondents $\times$ years are overweight, only $48.17 \%$ of the female respondents $\times$ years are overweight. The $7.42 \%$ male-female difference in overweight is statistically significant at $1 \%$ significance level (calculated $t$-value with 2,901.55 degrees of freedom of 4.01). These figures resemble the 2014 national average of 54.5\% who are overweight (Israeli Central Bureau of Statistics (CBS), 2016: Statistical Abstract of Israel, page 53). 


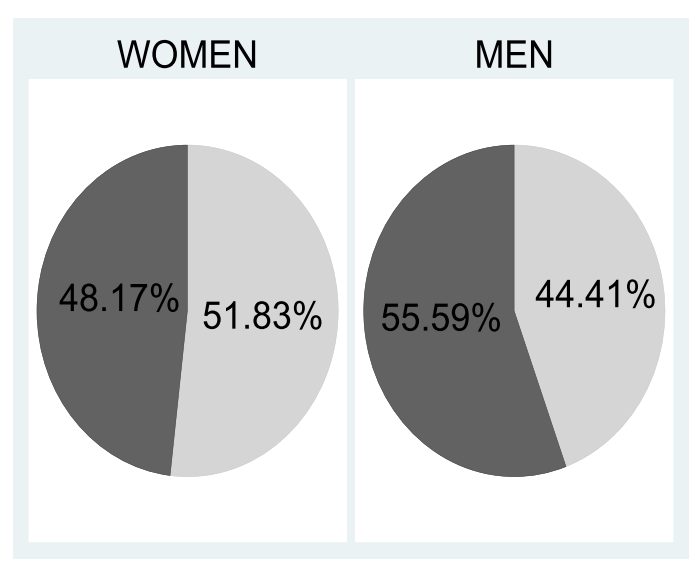

Figure 1. Distribution of Overweight across Gender

Notes: The left (right) figure refers to 1,447 Obs.xYears of females and 1,457 Obs. $\times$ Years of males who reported whether they suffer from traffic noise or not. Overweight is defined as $\mathrm{BMI} \geq 25$. The darker (brighter) color represents the percentage of Obs. $\times$ Years with (without) overweight. The $7.42 \%$ male-female difference in overweight is statistically significant at $1 \%$ significance level (calculated $t$-value with 2,901.55 degrees of freedom of 4.01).

Referring to the age variable, we focus on adult family members, whose age is 21 years or older. Given the three-year compulsory military service in Israel for males, we shifted the lowest bound from 18 years to 21 years. The sample mean is 43.58 years and the standard deviation is 16.46 years. The minimum is 21 years and the maximum is 80 years (AGE). Referring to the family size, the average household includes about four persons. The minimum is 1 person and the maximum is 11 persons (HHSIZE).

Finally, the sample contains an extensive series of environmental characteristics associated with the residential dwelling unit providing proxies for negative or positive externalities. The average number of exposures of the housing unit is about three, where the minimum is one and the maximum is four, namely, west, east, north and south (EXPOSURES). Of the 2,903 respondents $\times$ years, $18.43 \%$ view a green space in an urban area from the largest window (GREEN_SPACE), $41.73 \%$ report on traffic noise (TRAFFIC_NOISE). The view from the largest window of $23.01 \%$ is a highway (VIEW_HIGHWAY), and of $63.66 \%$ is an internal road (VIEW_INTERNAL).

\section{Methodology and Results}

\subsection{The Empirical Model}

The empirical model estimated separately for adult female and male respondents above 20 years is given by the following equations:

$$
\begin{aligned}
\ln (B M I) & =\alpha_{1} A G E+\alpha_{2} A G E \_S Q+\alpha_{3} H H S I Z E+\alpha_{4} \text { ENVIRONMENTAL } L_{1}+\alpha_{5}+D \vec{\delta}_{1}+u_{1} \\
\text { BMI } 25 & =\beta_{1} A G E+\beta_{2} A G E \_S Q+\beta_{3} H H S I Z E+\beta_{4} E N V I R O N M E N T A L_{2}+\beta_{5}+D \vec{\delta}_{2}+u_{2}
\end{aligned}
$$

Where $\ln (B M I)$, and $B M I 25$, the dependent variables, are the natural logarithm of the BMI, and a dummy variable that equals 1 for overweight $(B M I \geq 25)$ and 0 otherwise; The 
independent demographic variables include: $A G E, A G E \_S Q \quad\left(=A G E^{2}\right)$, which permit non-monotonic variation with respect to the dependent variable (e.g., Greene, 2012: 156-157), and HHSIZE; The environmental features include:

ENVIRONMENTAL $L_{1}=[$ GREEN_SPACE $] ;[$ TRAFFIC_NOISE $] ;$

$\left[\right.$ VIEW_HIGHWAY]; [VIEW_INTERNAL]; and ENVIRONMENTAL $L_{2}=[$ EXPOSURES $]$;

[GREEN_SPACE]; [TRAFFIC_NOISE]; [VIEW_HIGHWAY]; [VIEW_INTERNAL. These variables provide proxies to negative (positive) environmental externalities. The possibilities of using the BMI measure, and estimating the probability to become overweight $(B M I \geq 25)$ provide unique ways to test the research hypothesis, according to which BMI is expected to rise (drop) significantly with negative (positive) externalities.

Each of the four (five) environmental characteristics in ENVIRONMENTAL $L_{1}$

$\left(E N V I R O N M E N T A L_{2}\right)$ is incorporated separately in the model. $\alpha_{1}, \alpha_{2}, \alpha_{3}, \alpha_{4}, \alpha_{5}$ and $\beta_{1}, \beta_{2}, \beta_{3}, \beta_{4}, \beta_{5}$ are parameters, $D$ is a row vector of individual effect dummies, $\vec{\delta}_{1}$ and $\vec{\delta}_{2}$ are column vectors of parameters and $u_{1}$ and $u_{2}$ are the stochastic random disturbance terms.

\subsection{Results}

Table 2 reports the estimation results of the random effect panel regressions given by equation (1). The dependent variable is $\ln (\mathrm{BMI})$, the natural logarithm of the BMI variable. This specification is useful to yield estimated coefficients in precent terms (See the discussions on the semi-logarithmic model in Johnston and Dinardo, 1997: 45-46; and Greene, 2012: 200-201). Following the F-statistics, which reject the null hypothesis that the coefficients of individual effect dummies are equal, all the regressions include dummies Fixed-Effects (for a discussion see Johnston and Dinardo, 1997: 391-395; Greene, 2012: 386-387). To correct for potential heteroskedasticity, robust standard errors are given in parentheses (for a discussion see Johnston and Dinardo, 1997: 162-166; Greene, 2012: 428-429). 
Table 2. Random-Effect Panel Regressions 2015-2016: $\ln (\mathrm{BMI})$ Stratified by Gender, Cohort and Environmental Characteristics

\begin{tabular}{|c|c|c|c|c|c|c|c|c|}
\hline & $(1)$ & $(2)$ & (3) & (4) & (5) & (6) & (7) & $(8)$ \\
\hline VARIABLES & $\ln (\mathrm{BMI})$ & $\ln (\mathrm{BMI})$ & $\ln (\mathrm{BMI})$ & $\ln (\mathrm{BMI})$ & $\ln (\mathrm{BMI})$ & $\ln (\mathrm{BMI})$ & $\ln (\mathrm{BMI})$ & $\ln (\mathrm{BMI})$ \\
\hline \multirow[t]{2}{*}{ AGE } & $0.0106^{* * * *}$ & $0.0100^{* * *}$ & $0.0105^{* * * *}$ & $0.0099 * * *$ & $0.0106 * * *$ & $0.0099 * * *$ & $0.0106^{* * *}$ & $0.0100 * * *$ \\
\hline & $(0.0023)$ & $(0.0019)$ & $(0.0023)$ & $(0.0019)$ & $(0.0023)$ & $(0.0019)$ & $(0.0023)$ & $(0.0019)$ \\
\hline \multirow[t]{2}{*}{ AGE_SQ } & $-0.0001 * * *$ & $-0.0001 * * *$ & $-0.0001 * * *$ & $-0.0001 * * *$ & $-0.0001 * * *$ & $-0.0001 * * *$ & $-0.0001 * * *$ & $-0.0001 * * *$ \\
\hline & $(0.0000)$ & $(0.0000)$ & $(0.0000)$ & $(0.0000)$ & $(0.0000)$ & $(0.0000)$ & $(0.0000)$ & $(0.0000)$ \\
\hline \multirow[t]{2}{*}{ HHSIZE } & $0.0094 * * *$ & 0.0035 & $0.0092 * * *$ & 0.0027 & $0.0097 * * *$ & 0.0034 & $0.0097 * * *$ & 0.0032 \\
\hline & $(0.0030)$ & $(0.0023)$ & $(0.0030)$ & $(0.0024)$ & $(0.0030)$ & $(0.0023)$ & $(0.0030)$ & $(0.0023)$ \\
\hline \multirow[t]{2}{*}{ GREEN_SPACE } & $-0.0258^{* * *}$ & 0.0041 & - & - & - & - & - & - \\
\hline & $(0.0099)$ & $(0.0079)$ & - & - & - & - & - & - \\
\hline \multirow[t]{2}{*}{ TRAFFIC_NOISE } & - & - & $0.0230 * * *$ & $0.0229 * * *$ & - & - & - & - \\
\hline & - & - & $(0.0086)$ & $(0.0071)$ & - & - & - & - \\
\hline \multirow[t]{2}{*}{ VIEW_HIGHWAY } & - & - & - & - & -0.0005 & $0.0134 *$ & - & - \\
\hline & - & - & - & - & $(0.0102)$ & $(0.0075)$ & - & - \\
\hline \multirow[t]{2}{*}{ VIEW_INTERNAL } & - & - & - & - & - & - & -0.0004 & $0.0166^{* *}$ \\
\hline & - & - & - & - & - & - & $(0.0078)$ & $(0.0066)$ \\
\hline \multirow[t]{2}{*}{ Constant } & $2.8655^{* * *}$ & $2.9777 * * *$ & $2.8547 * * *$ & $2.9727 * * *$ & $2.8608 * * *$ & $2.9768 * * *$ & $2.8609 * * *$ & $2.9684 * * *$ \\
\hline & $(0.0482)$ & $(0.0402)$ & $(0.0481)$ & $(0.0402)$ & $(0.0480)$ & $(0.0402)$ & $(0.0481)$ & $(0.0406)$ \\
\hline Gender & FEMALES & MALES & FEMALES & MALES & FEMALES & MALES & FEMALES & MALES \\
\hline Dummies F-E & YES & YES & YES & YES & YES & YES & YES & YES \\
\hline F-Statistics & $3.85^{* * * *}$ & $3.92 * * *$ & $3.85^{* * *}$ & $3.86^{* * * *}$ & $3.89^{* * * *}$ & $3.90^{* * * *}$ & $3.90^{* * * *}$ & $3.89^{* * * *}$ \\
\hline $\begin{array}{l}\text { Observations } x \\
\text { Years }\end{array}$ & 1,446 & 1,457 & 1,447 & 1,457 & 1,446 & 1,457 & 1,446 & 1,457 \\
\hline Households & 961 & 954 & 962 & 956 & 961 & 954 & 961 & 954 \\
\hline R-squared & 0.135 & 0.0492 & 0.138 & 0.0614 & 0.129 & 0.0524 & 0.129 & 0.0531 \\
\hline Chi2 Statistics & $132.7 * * *$ & $95.19 * * *$ & $128.9 * * *$ & $109.4 * * *$ & $121.2^{* * * *}$ & $99.98 * * *$ & $121.1 * * *$ & $98.81 * * *$ \\
\hline
\end{tabular}

Figure 2 presents variations in projected BMI by age, gender, and environmental characteristics. All the graphs are based on the regression outcomes from Table 2. The two left (right) graphs refer to women (men). In each graph, the vertical axis is the projected BMI caculated as $\exp (\operatorname{proj}(\ln (B M I))$. The horizontal axis is the age in years.
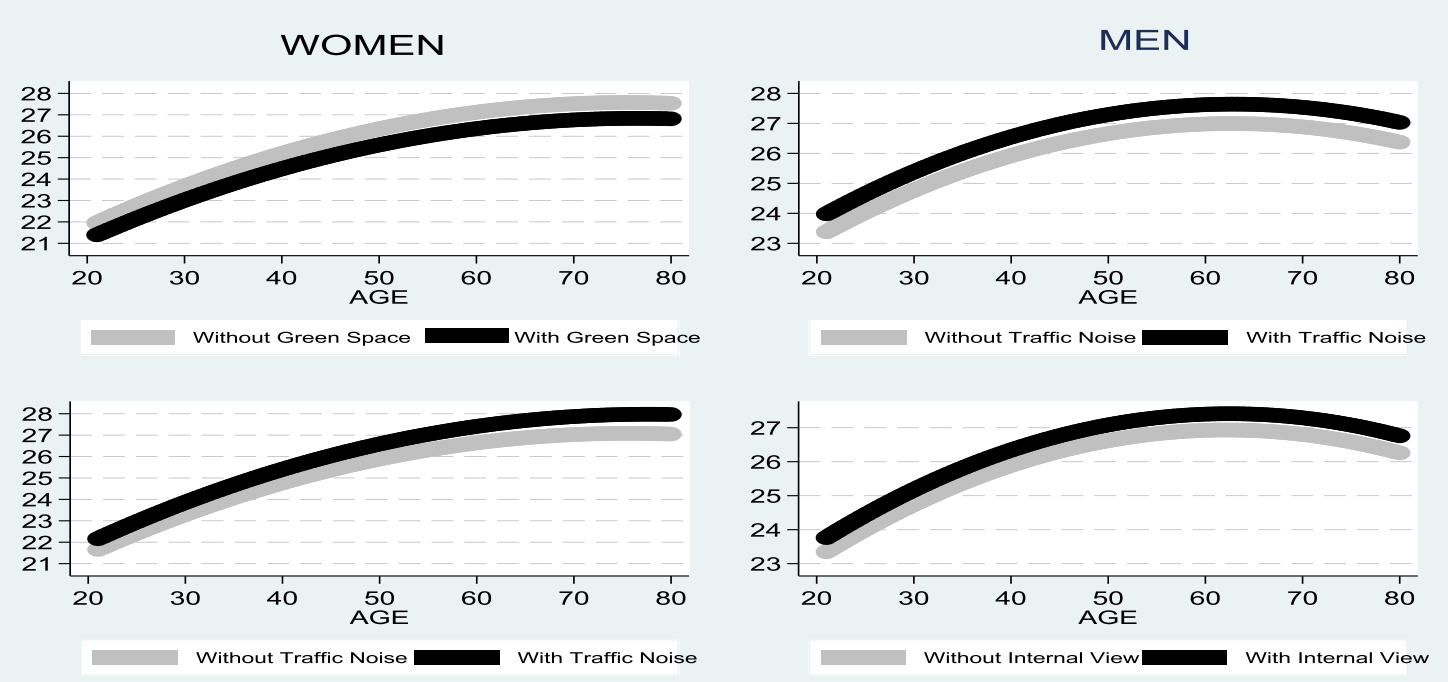

Figure 2. Projected BMI Stratified by Gender, Cohort and Environmental Characteristics 
While projected BMI drops significantly with positive environmental characteristics, such as a view of a green space from the largest window in an urban area (by $2.58 \%$, compared with women without this view), projected BMI rises significantly with negative environmental characteristics, such as traffic noise (by $2.30 \%$ for women and $2.29 \%$ for men) and a view of a highway and an internal road from the largest window (1.34\%-1.66\% for men without these views). As the graphs depart from each other with age, they visualize the percentage gap embedded in the semi-logarithmic model. As expected, projected BMI rises significantly with most cohorts, and reaches its peak for the group between 60-80 years. Finally, and unlike their males counterparts, projected BMI of female respondents rises significantly (at the $1 \%$ significance level) by $0.92 \%-0.97 \%$ for each additional child.

Table 3 reports the estimation results of the random effect panel regressions given by equation (2). The dependent variable, BMI25, equals 1 if as $\mathrm{BMI} \geq 25$ (overweight) and 0 otherwise. This Linear-Probability-Model (LPM) specification yields the projected probability to become overweight (for a discussion see Johnston and Dinardo, 1997: 414-418; Greene, 2012: 727-730). Following the F-statistics, which reject the null hypothesis that the coefficients of individual effect dummies are equal, all the regressions include dummies Fixed-Effects. To correct for an inherent heteroskedasticity in the LPM, robust standard errors are given in parentheses.

Figure 3 conceptualizes variations in projected probability of overweight with age, gender, and environmental characteristics. All the graphs are based on the regression outcomes from Table 3. The two left (right) graphs refer to women (men). In each graph, the vertical axis is the projected probability of overweight. The horizontal axis is the age in years.

Referring to cohort effect, the graphs show an increase in projected probability of overweight with age, where the peak is around 70\%-75\% for the 60-70 cohort. This tendency attenuates in the absence (presence) of negative (positive) environmental characteristics.

For the group of women respondents, projected probability of overweight drops significantly by $3.32 \%$ with each additional exposures (significant at the $1 \%$ significance level), and by $4.77 \%$ with a view of a green space in an urban area from the largest window (significant at the $10 \%$ significance level). Compared with the women's group, the signs of coefficients of these two positive environmental characteristics are the "correct" ones for the corresponding male group. However, these coefficients are statistically insignificant.

Referring to traffic noise, for both genders, projected probability of overweight rises significantly by $7.28 \%$ for women and $6.08 \%$ for men. Both coefficients are statistically significant at the $1 \%$ significance level. Other negative characteristics with significant coefficients for men include: VIEW_HIGHWAY and VIEW_INTERNAL, where projected probability of overweight rises by $6.18 \%$ with a highway view from the main window and by $4.92 \%$ with a view of an internal road from the largest window. Both coefficients are statistically significant at the $5 \%$ significance level. 
Table 3. Random-Effect Panel Regressions 2015-2016: Projected Probability of Overweight Stratified by Gender, Cohort and Environmental Characteristics

\begin{tabular}{|c|c|c|c|c|c|c|c|c|c|c|}
\hline & (1) & (2) & (3) & (4) & (5) & (6) & (7) & $(8)$ & (9) & $(10)$ \\
\hline VARIABLES & BMI25 & BMI25 & BMI25 & BMI25 & BMI25 & BMI25 & BMI25 & BMI25 & BMI25 & BMI25 \\
\hline \multirow[t]{2}{*}{ AGE } & $\begin{array}{l}0.0256^{*} \\
* *\end{array}$ & $\begin{array}{l}0.0299 * \\
* *\end{array}$ & $\begin{array}{l}0.0253 * \\
* *\end{array}$ & $\begin{array}{l}0.0288 * \\
* *\end{array}$ & $\begin{array}{l}0.0249 * \\
* *\end{array}$ & $\begin{array}{l}0.0287 * \\
* *\end{array}$ & $\begin{array}{l}0.0252 * \\
* *\end{array}$ & $\begin{array}{l}0.0285 * \\
* *\end{array}$ & $\begin{array}{l}0.0252 * \\
* *\end{array}$ & $\begin{array}{l}0.0289 * \\
* *\end{array}$ \\
\hline & $(0.0056)$ & $(0.0056)$ & $(0.0055)$ & $(0.0055)$ & $(0.0055)$ & $(0.0055)$ & $(0.0055)$ & $(0.0055)$ & $(0.0055)$ & $(0.0055)$ \\
\hline \multirow[t]{2}{*}{ AGE_SQ } & $\begin{array}{l}-0.0002 * \\
* *\end{array}$ & $\begin{array}{l}-0.0002 * \\
* *\end{array}$ & $\begin{array}{l}-0.0002 * \\
* *\end{array}$ & $\begin{array}{l}-0.0002 * \\
* *\end{array}$ & $\begin{array}{l}-0.0002 * \\
* *\end{array}$ & $\begin{array}{l}-0.0002 * \\
* *\end{array}$ & $\begin{array}{l}-0.0002 * \\
* *\end{array}$ & $\begin{array}{l}-0.0002 * \\
* *\end{array}$ & $\begin{array}{l}-0.0002 * \\
* *\end{array}$ & $\begin{array}{l}-0.0002 * \\
* *\end{array}$ \\
\hline & $(0.0001)$ & $(0.0001)$ & $(0.0001)$ & $(0.0001)$ & $(0.0001)$ & $(0.0001)$ & $(0.0001)$ & $(0.0001)$ & $(0.0001)$ & $(0.0001)$ \\
\hline \multirow[t]{2}{*}{ HHSIZE } & $\begin{array}{l}0.0347 * \\
* *\end{array}$ & 0.0130 & $\begin{array}{l}0.0305 * \\
* *\end{array}$ & $0.0137^{*}$ & $\begin{array}{l}0.0293 * \\
* *\end{array}$ & 0.0111 & $\begin{array}{l}0.0309 * \\
* *\end{array}$ & $0.0140^{*}$ & $\begin{array}{l}0.0310^{*} \\
* *\end{array}$ & $0.0132^{*}$ \\
\hline & $(0.0079)$ & $(0.0080)$ & $(0.0078)$ & $(0.0079)$ & $(0.0078)$ & $(0.0079)$ & $(0.0078)$ & $(0.0078)$ & $(0.0078)$ & $(0.0079)$ \\
\hline \multirow[t]{2}{*}{ EXPOSURES } & $\begin{array}{l}-0.0332 * \\
*\end{array}$ & -0.0020 & - & - & - & - & - & - & - & - \\
\hline & $(0.0136)$ & $(0.0138)$ & - & - & - & - & - & - & - & - \\
\hline \multirow[t]{2}{*}{$\begin{array}{l}\text { GREEN_SPAC } \\
\text { E }\end{array}$} & - & - & $-0.0477 *$ & -0.0024 & - & - & - & - & - & - \\
\hline & - & - & $(0.0283)$ & $(0.0305)$ & - & - & - & - & - & - \\
\hline \multirow[t]{2}{*}{$\begin{array}{l}\text { TRAFFIC_NOI } \\
\text { SE }\end{array}$} & - & - & - & - & $\begin{array}{l}0.0728 * \\
* *\end{array}$ & $\begin{array}{l}0.0608^{*} \\
* *\end{array}$ & - & - & - & - \\
\hline & - & - & - & - & $(0.0249)$ & $(0.0235)$ & - & - & - & - \\
\hline \multirow[t]{2}{*}{$\begin{array}{l}\text { VIEW_HIGHW } \\
\text { AY }\end{array}$} & - & - & - & - & - & - & -0.0063 & $\begin{array}{l}0.0618 * \\
*\end{array}$ & - & - \\
\hline & - & - & - & - & - & - & $(0.0303)$ & $(0.0285)$ & - & - \\
\hline \multirow[t]{2}{*}{$\begin{array}{l}\text { VIEW_INTER } \\
\text { NAL }\end{array}$} & - & - & - & - & - & - & - & - & 0.0246 & $\begin{array}{l}0.0492 * \\
*\end{array}$ \\
\hline & - & - & - & - & - & - & - & - & $(0.0233)$ & $(0.0245)$ \\
\hline \multirow[t]{2}{*}{ Constant } & $\begin{array}{l}-0.3266^{*} \\
* *\end{array}$ & $\begin{array}{l}-0.2651 * \\
*\end{array}$ & $\begin{array}{l}-0.3733 * \\
* *\end{array}$ & $\begin{array}{l}-0.2514 * \\
*\end{array}$ & $\begin{array}{l}-0.4000 * \\
* *\end{array}$ & $\begin{array}{l}-0.2670 * \\
*\end{array}$ & $\begin{array}{l}-0.3806 * \\
* *\end{array}$ & $\begin{array}{l}-0.2605 * \\
*\end{array}$ & $\begin{array}{l}-0.3983 * \\
* *\end{array}$ & $\begin{array}{l}-0.2827 * \\
*\end{array}$ \\
\hline & $(0.1202)$ & $(0.1274)$ & $(0.1160)$ & $(0.1238)$ & $(0.1160)$ & $(0.1234)$ & $(0.1161)$ & $(0.1236)$ & $(0.1173)$ & $(0.1237)$ \\
\hline Gender & $\begin{array}{l}\text { FEMAL } \\
\text { ES }\end{array}$ & MALES & $\begin{array}{l}\text { FEMAL } \\
\text { ES }\end{array}$ & MALES & $\begin{array}{l}\text { FEMAL } \\
\text { ES }\end{array}$ & MALES & $\begin{array}{l}\text { FEMAL } \\
\text { ES }\end{array}$ & MALES & $\begin{array}{l}\text { FEMAL } \\
\text { ES }\end{array}$ & MALES \\
\hline Dummies F-E & YES & YES & YES & YES & YES & YES & YES & YES & YES & YES \\
\hline F-Statistics & $2.87 * * *$ & $3.14 * * *$ & $3.03 * * *$ & $3.28 * * *$ & $3.02 * * *$ & $3.27 * * *$ & $3.05 * * *$ & $3.28 * * *$ & $3.04 * * *$ & $3.27 * * *$ \\
\hline $\begin{array}{l}\text { Observations } \times \\
\text { Years }\end{array}$ & 1,379 & 1,397 & 1,446 & 1,457 & 1,447 & 1,457 & 1,446 & 1,457 & 1,446 & 1,457 \\
\hline Households & 924 & 924 & 961 & 954 & 962 & 956 & 961 & 954 & 961 & 954 \\
\hline R-squared & 0.123 & 0.0396 & 0.110 & 0.0381 & 0.116 & 0.0456 & 0.107 & 0.0427 & 0.110 & 0.0415 \\
\hline Chi2 Statistics & $\begin{array}{l}156.2 * * \\
*\end{array}$ & $\begin{array}{l}70.26 * * \\
*\end{array}$ & $\begin{array}{l}144.1 * * \\
*\end{array}$ & $\begin{array}{l}70.70 * * \\
*\end{array}$ & $\begin{array}{l}145.8 * * \\
*\end{array}$ & $80 * * *$ & $\begin{array}{l}138.9 * * \\
*\end{array}$ & $\begin{array}{l}77.48 * * \\
*\end{array}$ & $\begin{array}{l}139.2 * * \\
*\end{array}$ & $\begin{array}{l}76.76^{* *} \\
*\end{array}$ \\
\hline
\end{tabular}

Notes: BMI25 equals 1 if as $B M I \geq 25$ (overweight) and 0 otherwise. Robust standard errors are given in parentheses. The F-statistics support the hypothesis that the coefficients of Dummies FE for households are not equal statistically. Robust standard errors are given in parentheses. * significant at the $10 \%$ significance level. ** significant at the 5\% significance level. $* * *$ significant at the $1 \%$ significance level). 


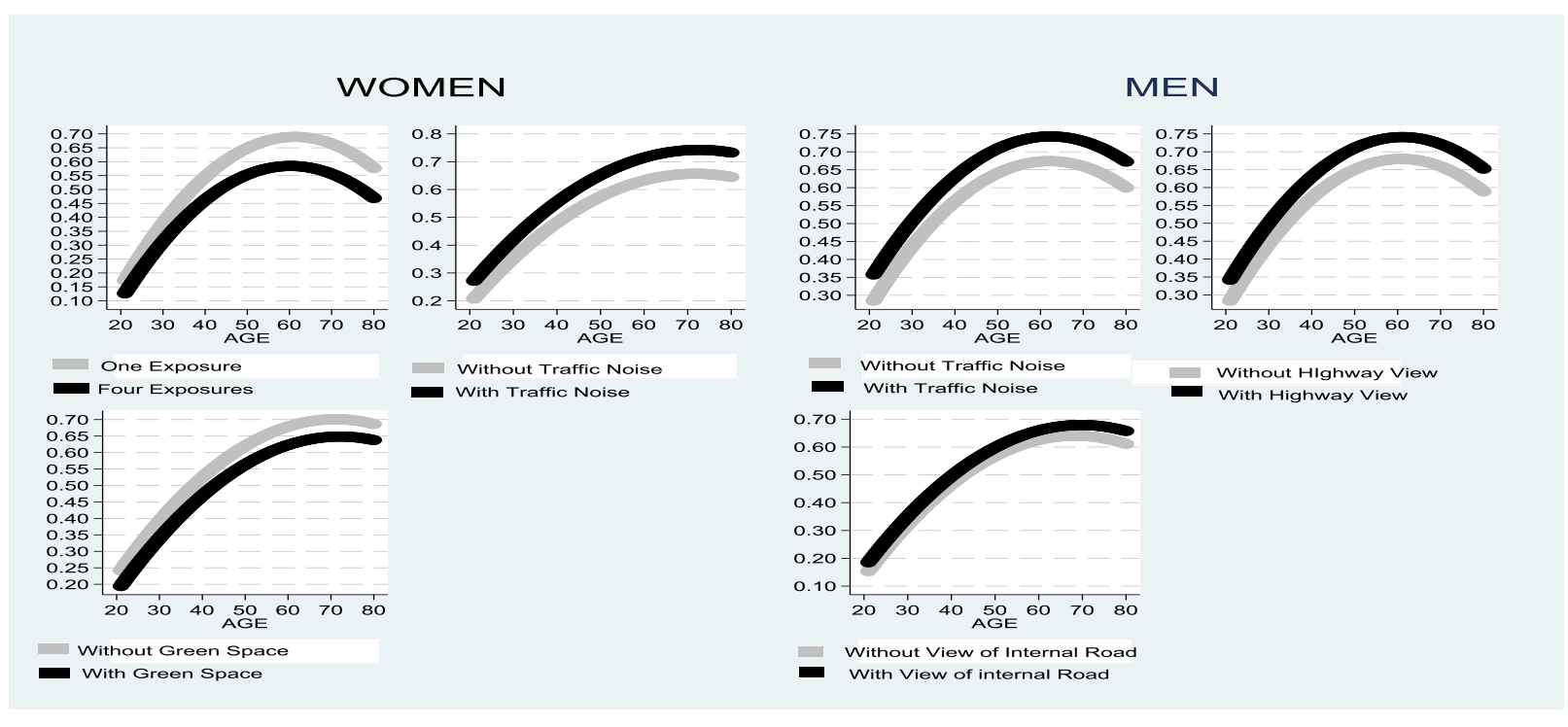

Figure 3. Projected Probability of Overweight Stratified by Gender, Cohort and Environmental Characteristics

Notes: All the graph are based on the regression outcomes from Table 3. The three left (right) graphs refer to women (men). The vertical axis is projected probabilities of overweight defined as as $\mathrm{BMI} \geq 25$. The horizontal axis is the age in years.

\section{Discussion}

The current study makes use of an extensive set of questions concerning the environmental characteristics of the housing unit asked within the framework of the 2015-2016 longitudinal survey conducted by the Israeli Central Bureau of Statistics. The survey also includes information regarding the weight, height, gender and age of each household member. The objective is to examine the impact of cohort, gender and environmental characteristics of the residential unit on overweight and obesity.

Results show that in the absence (presence) of negative (positive) environmental characteristics of the residential unit, projected BMI and probability of overweight rise (drop) significantly. Our findings supports those of Bodin et al., (2015) who found a reduction in the level of reported sleeping annoyance in housing units with a quiet side than those having at least at least one window facing a yard, garden or green space.

With the exception of traffic noise, the findings further indicate gender differences with respect to the former variables, namely, exposures and green space, and latter variables, namely, a view of a highway and an internal road.

The prominent public policy reprecussion is that a reduction in traffic noise, may improve residents' health, as they lead to a decrease in the prbability of overweight for both genders. Given that obesity and overweight have become such a pervasive risk factor for global mortality responsible for an estimated 3.2-5.0 million deaths annually (Sallis et al., 2016; World Health Organization report, 2018), this improvement should not be underestimated. A further implication includes the significant impact of positive characteristics (number of exposures and a view of a green space from the apartments largest window) on the probabity 
of overweight among women.

\section{Acknowledgements}

The authors are grateful to Israel Social Sciences Data Center (ISDC), the Hebrew University of Jerusalem for provision of project data and to Yifat Arbel and Miri Kerner for helpful comments.

\section{References}

Acemouglo, D., \& Joshua, A. (1999). How Large are the Social Returns to Education? Evidence from Compulsory Schooling Law. NBER, Working Paper 7444, 1-45. [Online] Available: http://www.nber.org/papers/w7444

Adachi-Mejia, A. M., Lee, C., Lee, C., Carlos, H. A., Saelens, B. E., Berke, E. M., \& Doescher, M. P. (2017). Geographic variation in the relationship between body mass index and the built environment. Preventive Medicine, 100, 33-40.

https://doi-org.elib.openu.ac.il/10.1016/j.ypmed.2017.03.018

Arbel, Y., Fialkoff, C., \& Amichai, K. (2018). What is the optimal housing choice for a minimal BMI? Economics Bulletin, 38(3), 1313-1337.

Bodin, T., Björk, J., Ardö, J., \& Albin, M. (2015). Annoyance, Sleep and Concentration Problems Due to Combined Traffic Noise and the Benefit of Quiet Side. International Journal of Environmental Research and Public Health, 12, 1612-28.

https://doi-org.elib.openu.ac.il/10.3390/ijerph120201612

Creatore, M. I., Glazier, R. H., Moineddin, R., Fazli, G. S., Johns, A., Gozdyra, P., .. Gillian, L. B. (2016). Association of Neighborhood Walkability with Change in Overweight, Obesity, and Diabetes. JAMA, 315(20), 2211-2220.

https://doi.org/10.1001/jama.2016.5898

Greene, W. H. (2012). Econometric Analysis, Seventh Edition. Pearson Education Limited.

Hemmingsen, G. J., Møller, P., Jantzen, K., Jonsson, A. G., Albin, M., Wierzbicka, A., Gudmundsson, A., Loft, S., \& Rissler, J. (2015). Controlled Exposure to Diesel Exhaust and Traffic Noise-Effects on Oxidative Stress and Activation in Mononuclear Blood Cells. Mutation Research, 775, 66-71.

https://doi-org.elib.openu.ac.il/10.1016/j.mrfmmm.2015.03.009

Israeli Central Bureau of Statistics (CBS), (2016). Statistical Abstract of Israel.

Johnston, J., \& John, D. (1997). Econometric Methods, Fourth Edition. McGraw-Hill International Edition.

OECD/EU, Health at a Glance: Europe (2016). State of Health in the EU Cycle, OECD Publishing, Paris. http://dx.doi.org/10.1787/9789264265592-en

O’Sullivan, A. (2012). Urban Economics, Eight Edition. McGraw Hills International Edition.

Qin, X. Z., \& Jay, P. (2016). The Medical Cost Attributable to Obesity and Overweight in 


\section{Macrothink}

China: Estimation Based on Longitudinal Surveys. Health Economics, 25, 1291-1311. https://doi-org.elib.openu.ac.il/10.1002/hec.3217

Sallis, J. F., Cerin, E., Conway, T. L., Adams, M. A., Frank, L. D., Pratt, M., ... Neville, O. (2016). Physical Activity in Relation to Urban Environments in 14 Cities Worldwide: a cross-sectional Study. Lancet, 387, 2207-2217.

https://doi.org/10.1016/S0140-6736(15)01284-2

Stark, J. H., Neckerman, K., Lovasi, G. S., Quinn, J., Weiss, C. C., Bader, M. D., ... Rundle, A. (2014). The impact of neighborhood park access and quality on body mass index among adults in New York City. Preventive Medicine, 64, 63-68.

https://doi-org.elib.openu.ac.il/10.1016/j.ypmed.2014.03.026

World Health Organization. (2018). Global strategy on diet, physical activity and health. Geneva: World Health Organization. [Online] Available:

http://www.who.int/dietphysicalactivity/pa/en/.

\section{Copyright Disclaimer}

Copyright for this article is retained by the author(s), with first publication rights granted to the journal.

This is an open-access article distributed under the terms and conditions of the Creative Commons Attribution license (http://creativecommons.org/licenses/by/3.0/). 